\title{
NUEVAS TERMINACIONES PARA NUEVAS REALIDADES: PERFORMATIVIDAD, AFILIACIÓN Y ATENUACIÓN EN LA COMUNIDAD DE HABLA LGTBI
}

\author{
NEW ENDINGS FOR NEW REALITIES: PERFORMATIVITY, AFFILIATION \\ AND MITIGATION IN THE LGTBI SPEAKING COMMUNITY
}

\author{
Carles Navarro-Carrascosa \\ Universitat de València, España \\ Grupo EDi \\ Carles.Navarro@uv.es \\ https://orcid.org/0000-0002-0303-982X
}

\begin{abstract}
Resumen
Este artículo presenta un estudio sobre las terminaciones $-i /$-is y -e/-es en la comunidad de habla LGTBI. La motivación de esta investigación viene de la representación del género no binario en la lengua española, marcado recientemente por las terminaciones en - $e$, que además es utilizado para crear un plural inclusivo que evite el masculino genérico. En la misma línea, se han detectado usos, dentro de la comunidad de habla LGTBI, de otro grupo de terminaciones $(-i /-i s)$ que parecen anular la distinción de género.

Los datos han sido extraídos de una encuesta sociolingüística elaborada por el autor de este trabajo. En la parte sociolingüística se pretende perfilar el tipo de usuario de estas terminaciones, hacia quiénes van dirigidas y con qué intención. En la parte pragmática se analizarán
\end{abstract}

\begin{abstract}
This article presents a study on the $-i /-i$ and $-e /-$ es endings in the LGTBI-speaking community. The motivation for this research comes from the representation of non-binary gender in the Spanish language, recently marked by the $-e$ endings, which are also used to create an inclusive plural that avoids the generic masculine. Along the same lines, uses have been detected, within the LGTBI-speaking community, of another group of endings $(-i /-i s)$ that seem to nullify the gender distinction.

The data have been extracted from a sociolinguistic survey carried out by the author of this work. In the sociolinguistic part, the aim is to outline the type of user of these endings, towards whom they are addressed and with what intention. On the pragmatic side, the
\end{abstract}

Para citar este artículo: Navarro-Carrascosa, Carles (2021). Nuevas terminaciones para nuevas realidades: performatividad, afiliación y atenuación en la comunidad de habla LGTBI. ELUA, 35: 179-201. https://doi.org/10.14198/ELUA2021.35.9

Recibido: 13/04/2020, Aceptado: 09/12/2020

(C) 2021 Carles Navarro-Carrascosa 
las funciones que se activan con el uso de estas terminaciones, centrando el análisis en la performatividad, la atenuación y la afiliación.

PALABRAS CLAVE: lingüística queer; género no binario; performatividad; afiliación, atenuación. functions that are activated with the use of these endings will be analyzed, focusing the analysis on performativity, mitigation, and affiliation.

KEYWORDS: queer linguistics; non-binary gender; performativity; affiliation; mitigation.

\section{INTRODUCCIÓN}

En la última década, dos movimientos sociales relacionados con las identidades sexuales y de género se han hecho un hueco en los medios de comunicación y han transmitido a la sociedad una problemática que está muy relacionada con el ámbito lingüístico. Estos movimientos vienen encabezados por dos sectores sociales: por un lado, el feminismo, que reclama, a nivel lingüístico, más presencia del género femenino, desplazando, así, el uso del masculino genérico, con el que sus activistas no se sienten representadas; por otro, el colectivo $\mathrm{LGTBI}^{1}$, que también reivindica el derecho a la libertad sexual y a la libre identidad de género. Parte de este colectivo, además, aboga por la ruptura de la dicotomía de género (masculino-femenino) y defiende la posibilidad de identificarse fuera de la misma, definiéndose como personas no binarias y reclamando una opción lingüística que los represente (este último colectivo será el eje de esta investigación).

Es así como este sector de la comunidad LGTBI ha conseguido que hayan ido apareciendo nuevas terminaciones gramaticales, entre otros fenómenos lingüísticos ${ }^{2}$, que hacen referencia a un género gramatical nuevo, el no binario, que responde a estas nuevas identidades.

Estas formas, en otras lenguas, ya se han regularizado en el ámbito legislativo de algunos países como Suecia y Holanda; además, se incluyen en algunas de sus obras lexicográficas ${ }^{3}$. No ha sucedido lo mismo en el caso de la lengua española, donde la normativa académica no reconoce un género que se salga de la dicotomía masculino-femenino. No obstante, algunos miembros de la comunidad de habla LGTBI ya están empezando a usar algunas formas gramaticales nuevas para incluir esas nuevas identidades y que puedan ser representadas en el habla. Es el caso de la terminación en -e para adjetivos y sustantivos, como alternativa a la - $o$ del masculino y la - $a$ del femenino; o la terminación en - $i$, que también es utilizada en muchos contextos comunicativos indistintamente del género del receptor. Ambas formas parecen desempeñar funciones comunicativas diferentes, como se ilustrará más adelante.

\section{OBJETIVOS}

Este trabajo se plantea con varios objetivos principales:

1. Presentar todas las formas que se utilizan en la lengua española, tanto a nivel escrito como a nivel oral, para cumplir los objetivos lingüísticos de los dos movimientos sociales mencionados: el feminismo y el activismo LGTBI.

\footnotetext{
1 Siglas que se corresponden con el movimiento de lesbianas, gais, transexuales, bisexuales e intersexuales.

2 Por ejemplo, la aparición de pronombre personales neutros, inexistentes en la lengua española y no reconocidos por la RAE, de los que se hablará más adelante en este mismo trabajo.

3 Como en el Diccionario de la Academia Sueca.
} 
2. De las formas más usadas y más consolidadas en el activismo LGTBI, se establecerán los perfiles de los hablantes que las utilizan, así como los contextos más habituales de uso de las mismas.

3. Definir los objetivos en el uso de estas formas; fundamentalmente, entre el plural inclusivo (que pretende evitar el uso del masculino genérico) y la representación del género no binario.

4. Realizar un análisis pragmalingüístico para enumerar las diferentes funciones pragmáticas que desempeñan en el habla cada uno de estos grupos de terminaciones.

5. Por último, se comprobará si el grupo de terminaciones - $i$-is y el grupo -e/-es cumplen ambas la función lingüística del género inclusivo o si, por el contrario, el primer grupo simplemente tiene un carácter coloquial y desarrolla funciones diferentes; además, se clarificará si los dos grupos son característicos de la comunidad de habla LGTBI.

\section{METODOLOGÍA}

Para poder llevar a cabo esta investigación, el autor ha hecho uso de un corpus de elaboración propia en el que se recogen muestras de habla del colectivo LGTBI y que está formado por encuestas y grabaciones (de entrevistas semidirigidas y conversaciones coloquiales). Para este trabajo, se han utilizado los siguientes documentos del corpus:

1. 20 entrevistas semidirigidas, todas ellas grabadas por pares en Valencia, Madrid y Barcelona, a lo largo de los años 2018 y 2019. Todos los informantes tenían pleno conocimientos de que la entrevista estaba siendo registrada por el investigador.

2. Además, se han completado las muestras reales de habla con 200 publicaciones en redes sociales (especialmente Facebook, Twitter y Whatsapp) en las que se utilizaban las terminaciones analizadas. Muchos de los usuarios de las RR.SS. son personas pertenecientes al colectivo LGTBI y utilizan estos medios de comunicación para representar y construir sus identidades a través de publicaciones de actos de habla performativos, que han sido objeto de análisis.

3. 478 respuestas a una encuesta que fue circulada para toda la Península Ibérica por redes sociales y gracias a la colaboración de asociaciones y ONG especializadas en ayuda y visibilización del colectivo LGTBI. El objetivo del cuestionario es obtener información sobre los usuarios de las nuevas terminaciones de género. Se consideran importantes las variables edad, género y orientación sexual, entre otros factores propios de una investigación sociolingüística. Solo se han contabilizado y tenido en cuenta para este estudio las respuestas de los encuestados pertenecientes a la comunidad de habla LGTBI.

\section{MARCO TEÓRICO}

El marco teórico en el que se incluye este trabajo es la lingüística queer, disciplina que se enmarca dentro de la llamada teoría queer.

La teoría queer estudia la pertinencia "de reafirmar identidades que los grupos dominantes habían naturalizado y utilizado contra los propios individuos" (Vélez-Pellegrini 2008: 424), de estudiar las identidades sexuales y de género que se salen de la normatividad sexual, es 
decir, la heterosexualidad y las identidades cisgénero ${ }^{4}$. Analiza, también, “aquellas posiciones subjetivas que se hallan en los límites de la norma social y cultural" (Balza 2009: 234).

En esa misma línea, la lingüística queer se encarga de investigar las formas y recursos lingüísticos que son utilizados para construir y/o fortalecer esas identidades. En este sentido, Alberto Mira (2000: 245) señala que "the construction of a social identity is mostly about its expression", con lo que se espera que los grupos sociales que representan a determinadas subculturas se comporten de una manera determinada para diferenciarse del resto, identificarse con el propio grupo y construir una identidad colectiva. Estas actitudes también son lingüísticas.

\subsection{Sexo y género}

Dentro del marco de la teoría queer y la lingüística queer, se establece una diferencia muy clara entre los conceptos sexo y género. Tradicionalmente, se ha establecido una clasificación social fundamental entre sexos que ha derivado en la dicotomía masculino-femenino, dentro de la cual ambos lados tienen características opuestas, habitualmente también enmarcadas en binarismos (por ejemplo, fuerte-débil). Las diferencias que se establecen entre los dos polos (el masculino y el femenino) son, al mismo tiempo, complementarias entre sí. De hecho, se considera que la construcción de la masculinidad hegemónica se hace de acuerdo con tres negaciones: el hombre no es mujer, no es infante y no es homosexual (Herdt 1981, 1988; Godelier 1986; Badinter 1992; Gilmore 1994; Connell 1997; Kimmel 1997).

Es así como se establecen una serie de características que definirán ambos sexos en función de los roles o comportamientos que deben desarrollar los miembros de cada uno, según las convenciones sociales. Los de género masculino deben ser fuertes, valientes, inteligentes, dominantes, rudos, agresivos, productivos... mientras que a los miembros del sexo femenino se le adjudican características como debilidad, belleza, sensibilidad, pasividad, sumisión, coquetería, ternura, reproducción, entre otras (Cabral y García 2000).

En las últimas décadas han crecido los movimientos feministas y LGTBI y han surgido estudios que deconstruyen esta clasificación social hegemónica, tales como la ya mencionada teoría queer, promovida, entre otros, por Judith Butler. Así, se empieza a diferenciar entre sexo y género. El sexo empieza a ser considerado como una cuestión estrictamente biológica que se relaciona con los genitales de cada individuo, como señalan Moreno y Pichardo (2006: 146):

[el sexo] se refiere a las características biofisiológicas de los individuos que son marcadas culturalmente para definir lo que es un hombre y una mujer. En el caso de nuestra cultura occidental, se refiere a la genitalidad (pene-vagina), las gónadas (testículos-ovarios), la genética (cromosomas XX ó XY) o los llamados rasgos sexuales secundarios cuyo desarrollo tiene normalmente un origen hormonal (pechos, caderas, vello, masa muscular...).

Mientras que el género está relacionado con el concepto de identidad, como apuntan también Moreno y Pichardo (2006: 146):

4 Se denomina así a la correspondencia entre el sexo biológico y el género identitario.

5 "La construcción de una identidad social se hace principalmente desde la expresión" (traducción del autor). 
[el concepto de género] remite a los diferentes contenidos socioculturales que se dan en esas características biofisiológicas entre hombres y mujeres estableciendo comportamientos, actitudes y sentimientos masculinos y femeninos y jerarquizándolos de modo que se da mayor valor para los que se identifican con lo masculino.

De este modo, estos movimientos establecen que una persona puede nacer con un sexo biológico que no se corresponde con su identidad de género. Para esto, el papel del lenguaje también es fundamental, tal y como apunta Vellez-Pelligrini (2008: 425):

el sexo es ficticio y que, al igual que el género, se va adquiriendo a través de la propia presión que ejerce la lingüística a través del discurso y los procesos porcentuales que emanan de un sistema epistémico históricamente contingente. Función de la modernidad y de la Razón Patriarcal fue fragmentar el cuerpo a través del propio lenguaje, creando asimetrías entre los hombres y las mujeres y cómo no, entre la heterosexualidad y la homosexualidad. Así, el lenguaje ha creado efectos de realidad y a fuerza de nombrar la diferencia ha terminado por generar la apariencia de una diferencia natural.

\subsection{Nuevas identidades}

En la actualidad muchas personas afirman no identificarse con la dicotomía de género masculino-femenino ni con los roles que tradicionalmente se han asignado a cada uno de ellos. Esta no-identificación con los géneros establecidos puede deberse a dos motivos: por un lado, una razón biológica, es decir, una persona que haya nacido con ambos órganos sexuales y decida no someterse a ninguna intervención quirúrgica que la asigne a uno de los dos; por otro lado, una cuestión identitaria a la que ya se ha hecho mención y por la que alguien puede no sentirse identificado con ninguno de los roles de género establecidos y siente, por tanto, que está fuera del binarismo.

Es en estos casos cuando la teoría queer, en esa deconstrucción de la sociedad heteropatriarcal, desmonta (o intenta desmontar) la llamada dicotomía de género en la que solo tienen cabida dos polos opuestos (masculino-femenino) y propone reinventar el concepto de género para que nuevas identidades puedan hacerse hueco y se vean, también, representadas.

Se conoce como personas no binarias o intergénero ${ }^{6}$ a aquellas que no se sienten ni hombres ni mujeres; y a aquellas que tienen ambos órganos reproductores se las conoce como intersexuales ${ }^{7}$, que para Pérez Fernández-Figares (2010: 102) es una "variante biológica natural". En el ejemplo (1) se recoge parte del testimonio de una de las personas entrevistadas que se denominó como persona de género fluido:

(1) C:y me lo hizo plante- y me- y me lo hacía como cuestionarme hasta a mí mismo/ y entonces llegó un punto en el que dije/// después de meses y meses dándole vueltas a la cabeza en plan/ qué soy/ qué no soy y qué tal/ llegó un punto en el que dije/ mira/ a partir de aqui me voy a dejar llevar $\rightarrow$ y no voy a intentar categorizarme porque lo único que me genera es mucha ansiedad $\downarrow$

6 Existen otras nomenclaturas para hacer referencia a las personas no binarias, como género fluido o gender fluid o outgender, entre otras.

7 "Referido a la condición del individuo que tiene rasgos de los dos sexos, masculino y femenino, mezclados" Rodríguez, 2008: 223 


\section{EL REFLEJO EN LA LENGUA}

Teniendo en cuenta esta nueva realidad y los movimientos sociales (tanto el del feminismo como el de la comunidad LGTBI) se puede contextualizar el surgimiento de distintas flexiones, por parte de dichas comunidades, que intentan agrupar todos los géneros en una sola flexión para evitar la discriminación lingüística. Estableceremos la distinción atendiendo a los dos niveles de lengua fundamentales: escrito y oral.

\subsection{El nivel escrito}

Surgen, en un primer momento, formas escritas que, aunque no tienen un equivalente oral, sí que simplifican el tratamiento del género a nivel escrito:

1. El símbolo@ se ha convertido en una terminación de género, a modo de fusión de las terminaciones masculina (-o) y femenina $(-a)$. A nivel escrito, facilita la escritura, evitando tener que repetir dos veces un mismo sustantivo o adjetivo, cambiando el género del mismo. Sin embargo, esta forma, a pesar de seguir siendo utilizado por algunos, procura problemas de oralidad. Además, aunque pretende ser inclusiva con el género femenino, sigue siendo una forma que refuerza el binarismo, lo que es contrario a las ideas defendidas por los movimientos transfeministas.

2. Aparecen, por tanto, otras formas que, gráficamente, intentan acoger en una sola terminación todas las identidades. Principalmente encontramos dos representaciones:

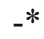

$-\mathrm{X}$

(2) Lo cierto es que hay tanto hablantes como académicos de la lengua (grupo A) quienes sostienen que es innecesario modificar esa norma. A otras y otros les parece insuficiente el masculino como genérico (grupo B), incluso excluyente e invisibilizador. Por otra parte, existen otrxs quienes no se asumen bajo identidades de género binarias masculino/femenino (grupo C). (Barrera y Ortiz 2007: 1)

Las más utilizada es la segunda $(-x)$. Pese a que la tendencia es aplicarla al final de las palabras, a modo de morfema de género, se han encontrado casos en los que la forma $-x$ aparece en el primer carácter de una palabra, por ejemplo, en sustantivos heterónimos en los que la diferencia de género viene en la raíz y no en la terminación:

(3) ¡Hola! Pregunta lingüística. ¿cuando hablas de traductores en inclusivo mantienes la $e$ o la cambias de algún modo? Por saber más estrategias (como la de xadres para padres y madres) ${ }^{8}$

\subsection{Nivel oral}

Más allá del lenguaje escrito, han surgido otras propuestas morfológicas que, por un lado, aparentan ser inclusivas para todos los géneros (o al menos conllevan cierta neutralidad de género). Así, aparecen morfemas nuevos, no normativos, pensados para el nivel oral, como,

8 Visto en Twitter (Fecha de publicación: 10 de septiembre de 2019). 
por ejemplo, el morfema - $i$. Este está menos desarrollado para el trato de género y podemos verlo también en otro tipo de palabras, como interjecciones:

(4) ¡Holi! ¿Alguien viene esta tarde al gimnasio? ${ }^{9}$

Este morfema se genera solo dentro del registro coloquial y, aunque muchos de los registros que se han recogido para esta investigación son publicaciones escritas en redes sociales, todas ellas simulan oralidad. Además, como se demostrará en el siguiente apartado, es especialmente utilizado a modo de plural inclusivo (para incluir todos los géneros, binarios o no binarios, y no para hacer referencia a las nuevas realidades señaladas más arriba, especialmente por esa connotación de neutralidad que mencionábamos). Además, su uso no es exclusivo de la comunidad de habla LGTBI, aunque sí es en el discurso de sus miembros donde más aparece (como se confirmará en el apartado 7).

Tras nuestro análisis, se puede confirmar que las funciones pragmáticas con las que se suele usar esta forma son dos: por un lado, se detecta un carácter afiliativo con el que el hablante pretende crear proximidad con su interlocutor o interlocutores:

(5) Puti, que lo llevo muy mal...10

(6) Amiguis, esta noche iremos al cedro a hacernos unas tapas, por si os animáis ${ }^{11}$

Y, por otro lado, se han encontrado diversos ejemplos que se incluyen dentro de la categoría pragmática de la atenuación, como ya se desarrollará en el apartado 8:

(7) Buenas noches, en especial a xxxxxx que está enfadadi ${ }^{12}$

(8) No estoy enfadadi, solo puntualizo, para que no se confunda lo que es realmente el Independentismo $^{13}$

Este morfema no aparece únicamente como flexión de sustantivos y adjetivos, como en (5), (6), (7) y (8), sino que también se han encontrado ejemplos en los que aparece tanto en interjecciones, como en (4), como en adverbios, como en (9):

(9) ¡Te veo pronti! $!^{14}$

\subsection{Niveles escrito y oral}

La flexión -e está mucho más extendida dentro del colectivo. Se trata de una terminación propuesta por García Meseguer (1977) para evitar el sexismo lingüístico del masculino genérico que, según él, no representaba a las mujeres. Esta forma se ha recuperado décadas más tarde, ante la necesidad de una parte del colectivo LGTBI que no se identifica ni con el género masculino ni con el femenino (denominadas personas de género no binario) de designarse bajo unas terminaciones que se ajusten mejor a su identidad (Wójtowicz, 2017;

9 Visto en WhatsApp (6 de septiembre de 2019).

10 Visto en Twitter (Fecha de publicación: 28 de agosto de 2019).

11 Visto en WhatsApp (23 de abril de 2019).

12 Visto en Twitter (Fecha de publicación: 12 de febrero de 2013).

13 Visto en Twitter (Fecha de publicación: 2 de marzo de 2019).

14 Visto en WhatsApp (23 de abril de 2019). 
Franco Martínez, 2019). Podemos encontrar esta terminación tanto a nivel oral como escrito, como en (10):

(10) A medida que vamos aprendiendo más sobre el coronavirus (COVID-19), queremos que les usuaries de Grindr tengan la mejor información para que podamos cuidarnos a nosotres mismes y a nuestras comunidades. $[\ldots]^{15}$

Únicamente se encuentra flexionada con sustantivos y adjetivos, como una terminación de género alternativa a las las flexiones normativas (masculina y femenina).

Además, se han elaborado pronombres para este género gramatical no binario, como se indica en el cuadro 1. Esta elaboración pronominal es una imitación de lo que ya se ha hecho en otros países europeos, como Suiza, Holanda o Bélgica, que han creado un pronombre neutro para sus respectivas lenguas con el que aquellas personas que se sienten fuera de la dicotomía de género masculino-femenino pueden sentirse lingüísticamente representadas. Estos pronombres ya aparecen en algunos impresos o documentos burocráticos junto al masculino y al femenino, como una tercera opción a completar por los usuarios (Navarro Carrascosa 2020).

\begin{tabular}{|c|c|c|}
\hline & Singular & Plural \\
\hline $1^{\text {a }}$ persona & & Nosotres \\
\hline $2^{\text {a }}$ persona & & Vosotres \\
\hline $3^{\text {o }}$ persona & Elle & Elles \\
\hline
\end{tabular}

Cuadro 1. Pronombres personales del género no binario

Estos pronombres, y sus terminaciones en -e (ejemplificadas en el cuadro 2) han nacido en los movimientos transfeministas, tal y como se apunta en Navarro-Carrascosa (2020).

\begin{tabular}{|c|c|c|c|}
\hline & Masculino & Femenino & Neutro \\
\hline Singular & - o & -a & -e \\
\hline Plural & -os & -as & -es \\
\hline
\end{tabular}

Cuadro 2. Flexiones normativas de género gramatical en español junto con las flexiones de género no binario

En el caso de la flexión en singular, el objetivo de los hablantes al aplicarlas a la lengua es hacer referencia a las personas no binarias en la mayoría de los casos:

(11) B: pero es verdad que uno de los que estaban $\rightarrow$ bueno/ une ¿no? porqueee- a mí me cuesta mucho utilizar la $e$ perooo/ nos lo pedían $[\ldots]$

En el caso de los sustantivos en plural, se han encontrado enunciados en los que parece hacerse referencia al género no binario (12) o como forma inclusiva para todos los géneros (sobre todo el masculino y el femenino), como se ilustra en (13):

15 Notificación a los usuarios de la aplicación para móviles Grindr, durante la crisis sanitaria de la Covid-19 (13 de marzo de 2020). 
(12) No se identifican ni como hombres ni como mujeres; en esa nomenglatura no se sienten cómodes.

(13) Aquelles que subís fotos y esperáis aprobación normativa promovéis la discriminación a todes les que salgan de la asfixiante norma que promueve la bulimia, anorexia, etc.

La pregunta que se plantea a continuación es cuál es el uso más extendido de estos grupos de flexiones $(-i /-i s$ y $-e /-e s)$, a la que se intentará dar respuesta en el siguiente apartado.

\section{ANÁLISIS}

El análisis que se propone para este trabajo es doble: por un lado, un repaso cualitativo a los usos de las dos terminaciones, en los que se destacará las funciones que se desarrollan en ellas (la atenuación, la afiliación y la performatividad); en segundo lugar, se presentará un análisis cuantitativo con los resultados de una encuesta sociolingüística en la que se han formulado algunas preguntas relativas al uso de ambas terminaciones.

\subsection{Funciones}

La atenuación es la categoría pragmática que pretende mitigar la fuerza ilocutiva de determinados actos de habla. Briz $(1995,1998,2003)$ diferencia entre la atenuación de lo dicho, que consiste en expresar de forma vaga el contenido de la proposición; y la atenuación del decir.

La afiliación es un proceso por el cual el hablante se identifica con un determinado grupo o comunidad y pretende convertirse en miembro del mismo (Bravo, 1999; Bonnin, 2019). Los hablantes de una lengua utilizan estrategias lingüísticas que les permiten identificarse con los miembros de una determinada comunidad y les facilita pasar a formar parte de esta. El objetivo es construir vínculos, aunque sean temporales, pues «la acción afiliativa tiene una orientación prosocial, porque construye un vínculo entre el hablante y quien lo realiza, basado en una identificación —al menos parcial — con su punto de vista o perspectiva» (Bonnin, 2019: 237).

En cuanto a la performatividad, es una estrategia que se asienta en la teoría de los actos de habla de Austin (1971), a través de las enunciaciones y las repeticiones de estas, «el discurso se realiza por las acciones que encarna y produce» (González Montero, 2009: 34). Una de las autoras que más trabaja la performatividad en cuestiones de género es Judith Butler (1990, 2002, 2007, 2009). La idea de Butler con la performatividad es que algunas concepciones (como el sexo, el género, etc.) son culturalmente construidos a través de la repetición de actos performativos (tanto actuaciones como enunciados) que, al mismo tiempo, van conformando identidades y realidades.

\subsection{Análisis cualitativo}

Después del análisis cuantitativo de los dos grupos de terminaciones que neutralizan el género en la lengua española (-i/-is y -e/-es) hecho a partir de las encuestas, se concluye que las funciones que predominan en ambas son la atenuación y la afiliación, por un lado, mayormente representadas en el grupo de terminaciones $-i /-i s$; y la performatividad, por 
otro, que se incluye en las terminaciones -e/-es. El presente apartado se presenta como un análisis cualitativo que se ofrece tras la parte cuantitativa a tenor de los resultados de las encuestas, en el que se analizarán muestras de habla (orales y digitales) de enunciados con ambos grupos de terminaciones.

(14) ¿Quién juega al FFXIV o soy yo la única tonti? ${ }^{16}$

En (14) vemos un ejemplo de la atenuación de lo dicho, en la que se pretende reducir la carga negativa del adjetivo tonta para que la imagen de la propia emisora no se vea perjudicada.

(15) No me pudo haber tocado un humano mejor. Gracias por cuidar de todos, todas y todes ${ }^{17}$

En (15) tenemos un ejemplo de cómo la terminación -es construye una nueva forma lingüística para referirse a las personas de genero no binario. Así lo indica el hecho de que en el mismo enunciado se incluyan las formas en masculino y en femenino. Mientras que en (16) nos encontramos con un enunciado en el que la misma terminación responde al plural inclusivo:

(16) Confirmen si todes nos queremos dar de baja de la uni

El primer subapartado estudiará la atenuación en estas terminaciones, por lo que se centrará más en el grupo -i/-is; el segundo, describirá la performatividad que se produce con los enunciados que se forman con el grupo -e/-es.

\subsubsection{Grupo de terminaciones $-\mathrm{i} /$-is}

El uso del grupo de terminaciones -i/-is puede activar dos fenómenos: la atenuación, como se puede ver en los ejemplos (7), (8) y (14); y la afiliación, como se ilustra en (9).

\subsubsection{La atenuación}

La atenuación, tal y como la definen Briz y Albelda (2010: 237)

es una categoría pragmática cuya función consiste en minimizar la fuerza ilocutiva de los actos de habla y, con frecuencia, regula la relación interpersonal y social entre los participantes de la enunciación. Se emplea, pues, de manera estratégica para lograr las metas deseadas de la comunicación. Algunos de los valores que describen más concretamente esta operación lingüística son suavizar el mensaje, quitar relieve, mitigar, reparar o esconder la verdadera intención.

Como ya se ha señalado en apartados anteriores de este trabajo, en algunos enunciados en los que se utilizan las terminaciones $-i /$-is, el objetivo es la mitigación de la fuerza ilocutiva

16 Visto en Twitter (Fecha de publicación: 17 de septiembre de 2019).

17 Visto en Twitter (Fecha de publicación: 2 de abril de 2020). 
de enunciados que pueden afectar negativamente a la imagen del receptor, del referenciado o, incluso, del propio emisor:

(16) Si es que eres tonti pero eso no es culpa de Barcelona ${ }^{18}$

(17) Va tonti no te pongas así que hay muchos más torneos y todos sabemos que puedes. Ánimo y fuerza para el siguiente ${ }^{19}$

En (16), el emisor está increpando al receptor de su publicación en la red social Twitter, pero, a través de la terminación - $i$ del adjetivo, se reduce la carga negativa del insulto. En este caso, se presenta una atenuación hacia la imagen del receptor y se pretende evitar un conflicto que podría producirse sin la utilización de esta flexión. En (17) se presenta un acto de habla en el que la atenuación que facilita la terminación a través del adjetivo tonti está salvaguardando la imagen del propio emisor, que no quiere que su interlocutor piense que está siendo insultado. La diferencia que se encuentra entre ambos ejemplos es que, usando el mismo adjetivo, la intención del emisor de (16), que es un acto de habla asertivo, es insultar a su interlocutor, mientras que en (17) se usa el mismo adjetivo en un acto de habla directivo para tratar de mitigar la fuerza ilocutiva de los imperativos que aparecen en el enunciado.

Para buscar la atenuación de estos enunciados y poder analizarla, se han utilizado las pruebas presentadas por Villalba $(2018,2020)$ : ausencia, conmutación y solidaridad. La prueba de ausencia consiste en eliminar el elemento que se considera atenuante para comprobar si se producen cambios en la fuera ilocutiva; la prueba de conmutación sustituye el dispositivo mitigador por otro por el que se puede intercambiar para comprobar si hay cambios en el enunciado; por último, la prueba de solidaridad consiste en buscar otros elementos atenuadores en el enunciado. Obsérvense los siguientes ejemplos:

(18) Quién juega al FFXIV o soy la única tonti

(19) Puti, hablemos por wa que me aburro 20

(20) Me cago en la puti que no 1 lego ${ }^{21}$

En (18) tenemos un acto de habla asertivo en el que se está reduciendo la carga negativa del lexema tonta para salvaguardar la imagen de la propia emisora; si aplicamos la prueba de conmutación y mantenemos la flexión de género femenino (tonta), la fuerza ilocutiva del enunciado se presenta más agresiva, al igual que en el ejemplo (20), que es un acto de habla expresivo en el que se atenúa la fuerza ilocutiva de una expresión que suele comportar cierto enfado o agresividad a través de la terminación $-i$, probablemente con el objetivo de reducir la posible incomodidad que pueda producir en los receptores potenciales. En (19) vemos un acto de habla directivo en el que se pretende una reacción por parte del receptor a través de un imperativo. La posible amenaza que ello pueda implicar, además de la carga semántica negativa que puede conllevar el apelativo, es mitigada a través de la terminación $-i$ en este último; además, aplicando la prueba de solidaridad, encontramos otros elementos atenuadores, como es el acortamiento wa (por whatsapp). En el ejemplo (17), presentado

18 Visto en Twitter (Fecha de publicación: 8 de enero de 2015).

19 Visto en Twitter (Fecha de publicación: 29 de marzo de 2020).

20 Visto en Twitter (Fecha de publicación: 7 de mayo de 2014).

21 Visto en Twitter (Fecha de publicación: 20 de octubre de 2014). 
más arriba, con la prueba de ausencia se demuestra que al faltar la palabra tonti, el acto de habla directivo podría resultar más amenazante.

\subsubsection{La afiliación}

Por otro lado, como ya se adelantaba al principio de este apartado, la atenuación no es el único resultado que se puede generar con el uso del grupo de terminaciones - $i$-is, también podemos apreciar actos de habla afiliativos. La afiliación es un proceso por el cual un hablante se identifica con un determinado grupo o comunidad y pretende convertirse en miembro del mismo (Bonnin 2019). Los hablantes de una misma lengua utilizan estrategias lingüísticas de afiliación para introducirse dentro de un grupo o comunidad. El objetivo es construir vínculos, aunque sean temporales, ya que "la acción afiliativa tiene una orientación pro-social, porque construye un vinculo entre el hablante y quien la realiza, basado en la identificación -al menos parcial- con su punto de vista o perspectiva” (Bonnin 2019: 237).

(21) Amigui XXXX, nos merecemos una buena celebración antes, durante y después del examen de mañana ${ }^{22}$

En el ejemplo (21), el emisor y el receptor están viviendo una situación compartida (un examen al día siguiente de la emisión del enunciado). El emisor trata de aumentar la conexión entre ambos usando un apelativo y alterando la terminación del mismo a $-i$. En el uso de este grupo de terminaciones sucede lo que señalan Martín Zorraquiño y Portolés acerca del marcador discursivo hombre, es decir, "imprime un tono amistoso en la conversación; tiñe las relaciones entre los interlocutores de cierta familiaridad o complicidad" (1999: 4173).

Como ya hemos dicho, la flexión en -i/-is puede adaptarse a lexemas que no son sustantivos ni adjetivos, incluso a categorías gramaticales no susceptibles de ser flexionadas (como adverbios o interjecciones). En estos casos, aporta connotaciones afiliativas, como en (22):

(22) Holi, bonita semana de home office ${ }^{23}$

En muchas ocasiones, los lexemas que aplican estas terminaciones funcionan como apelativos. En estos casos, distinguimos dos grupos: apelativos formados con lexemas con carga semántica positiva y apelativos formados por palabras con carga negativa, como pueden ser insultos.

a) Palabras con connotaciones positivas

Se trata de interacciones que muestran un carácter afiliativo por sí mismo. En general, con una palabra de esta naturaleza, que muchas veces funciona como apelativo. En estos casos, los emisores evitan decir el nombre, como en (23), o añaden otro lexema que acompañe al nombre, como en (24), para utilizar un apelativo terminado en -i que reforzará la intención afiliativa:

22 Visto en Twitter (Fecha de publicación: 1 de julio de 2019).

23 Visto en Twitter (Fecha de publicación: 7 de abril de 2020). 
(23) Qué alegría tenerte cerca, amigui ${ }^{24}$

(24) amigui XXX, nos merecemos una buena celebración antes, durante y después del examen de mañana ${ }^{25}$

(25) Vente cuando quieras, guapi

En (25), la palabra guapi, del adjetivo guapo o guapa, aunque tiene un sentido positivo, en muchos casos es utilizada en un sentido irónico en actos de habla que suponen reproches o ataques:

(26) La llevas clara, guapo

De este modo, en (25), a través del uso de la terminación - $i$, se refuerza la idea de afiliación y se evita una interpretación negativa.

b) Palabras con fuerza ilocutiva degradadora

Son interacciones aparentemente descorteses que pretenden mostrar "solidaridad grupal" (Bernal 2008: 778). Estos actos, al no pretender causar ofensa, no son amenazadores de la imagen (Bernal 2008). Los estudios que más han estudiado el fenómeno de la afiliación en el lenguaje se centran en el argot juvenil, que tiene una actividad afiliadora muy alta (Zimmermann 2003) en la que se constata la identidad generacional. Esto es lo que sucede, por ejemplo, con el uso de la voz maricón entre interlocutores heterosexuales (Navarro-Carrascosa 2019).

La estrategia del uso de palabras ofensivas que, como señala Albelda (2004: 123) "podrían funcionar en otro contexto más formal como auténticos debilitadores de las relaciones sociales, pero que en estos casos no lo hacen" y añade que "en ocasiones, crean lazos interpersonales más fuertes y positivos".

En ambos casos, las terminaciones - $i$-is están acentuando esa fuerza interpersonal y positiva de estos actos de habla afiliativos. Son, por tanto, reforzadores:

(27) Tengo ganas de verte, puta

El entorno semántico de la locución tener ganas de verte hace pensar que el insulto puta adquiere esta función afiliadora, pensamiento que cobrará más fuerza si conocemos el contexto comunicativo y este está formado por dos personas que comparten una amistad y entre las que no hay ningún tipo de conflicto.

Sin embargo, con un ejemplo como (27), si no se conoce el contexto, se podría interpretar que el encuentro que busca el emisor es para tener una pelea con su emisor o emisora y, por tanto, se trataría de un acto de habla amenazante. Sin embargo, al usar la terminación $-i$ en el insulto, no hay duda de que no se trata de ningún acto de habla amenazante. La intención afiliadora, por tanto, queda reforzada:

(28) Tengo ganas de verte, puti

24 Visto en Twitter (Fecha de publicación: 26 de mayo de 2019).

25 Visto en Twitter (Fecha de publicación: 1 de julio de 2019). 


\subsubsection{Grupo de terminaciones -e/-es}

Varios son los autores que han investigado acerca de la performatividad lingüística. Todos ellos insisten en el proceso de la repetición (Butler 2002; Gutiérrez Lozano 2007; Felipe y Quintero 2012; Cano Abadía, 2013) como fundamental para construir o cambiar la realidad a partir del lenguaje. Esta idea de la repetición necesaria para configurar realidades explica el porqué de la irrupción en la lengua de las terminaciones de género no binario en - $e$, cuyo principal objetivo es romper con el binarismo de género. Así, cada vez se encuentran más publicaciones en redes sociales como las siguientes:

(29) Si os da cosa o algo mandadme un MD, que me estoy volviendo loque ${ }^{26}$

Según Butler, el siguiente elemento que configura la performatividad, después de la repetición, es la exclusión. Afirmando lo que se es, se confirma lo que no se es. En (30), el autor de la publicación pretende enfatizar que la persona de la que habla no es ni de género masculino, ni de género femenino:

(30) Le vi, elle es cantante, es linde ${ }^{27}$

Formando y utilizando estos pronombres y estas terminaciones, no solo se está creando una representación lingüística para que tengan cabida las personas de género no binario, sino que se está transformando la realidad, adaptándola a nuevas visiones de la misma en las que la dicotomía de género no tiene lugar. Como veíamos en las estadísticas, el 69,03\% de los encuestados afirmaba utilizar las terminaciones -e/-es con fines afiliativos, que, en este caso, podemos interpretar como afán de representar a aquellas personas que no encuentran formas lingüísticas para representarse.

También se ha señalado en apartados anteriores que las terminaciones -e/-es tienen una doble función según quiénes sean los usuarios que las utilicen. Además de referirse a personas no binarias, puede responder a una intención de crear una forma inclusiva que englobe tanto al género masculino como al femenino. Las terminaciones -e/-es suelen localizarse en actos de habla asertivos (30) y expresivos (31) cuando están haciendo referencia a personas de género no binario:

(31) No encuentro el lápiz de mi tableta, estoy jodidísime ${ }^{28}$

Cuando estas terminaciones son utilizadas de forma inclusiva (géneros masculino y femenino en una sola terminación) pretenden deconstruir la normativa académica del uso del masculino genérico:

(32) ¿Algune usáis $\{$-e $\}$ y cambiáis palabras como señores? ${ }^{29}$

26 Visto en Twitter (Fecha de publicación: 5 de agosto de 2019).

27 Visto en Twitter (Fecha de publicación: 14 de septiembre de 2019). Publicación en relación a la declaración de un cantante británico en la que se declaraba de género no binario.

28 Visto en Twitter (Fecha de publicación: 3 de septiembre de 2019).

29 Vito en Twitter (Fecha de publicación: 10 de septiembre de 2019). 
La premisa es que, añadiendo una terminación que de por sí es genérica, se respeta el principio de economía lingüística (argumento principal de la RAE en defensa del masculino genérico) y se elimina cualquier tipo de exclusión en la normativa gramatical de la lengua.

Como se ha ilustrado a partir de las encuestas, es mayor el uso de estas terminaciones para hacer uso del plural inclusivo $(82,22 \%)$ que para el género no binario $(80,00 \%)$, aunque de forma muy poco significativa.

\subsection{Análisis cuantitativo}

Según los datos que ha proporcionado la encuesta elaborada para el proyecto en el que se enmarca esta investigación, un $26,57 \%$ de los informantes usa las terminaciones $-i /$-is; y un $25,08 \%$ utiliza las formas -e/-es:

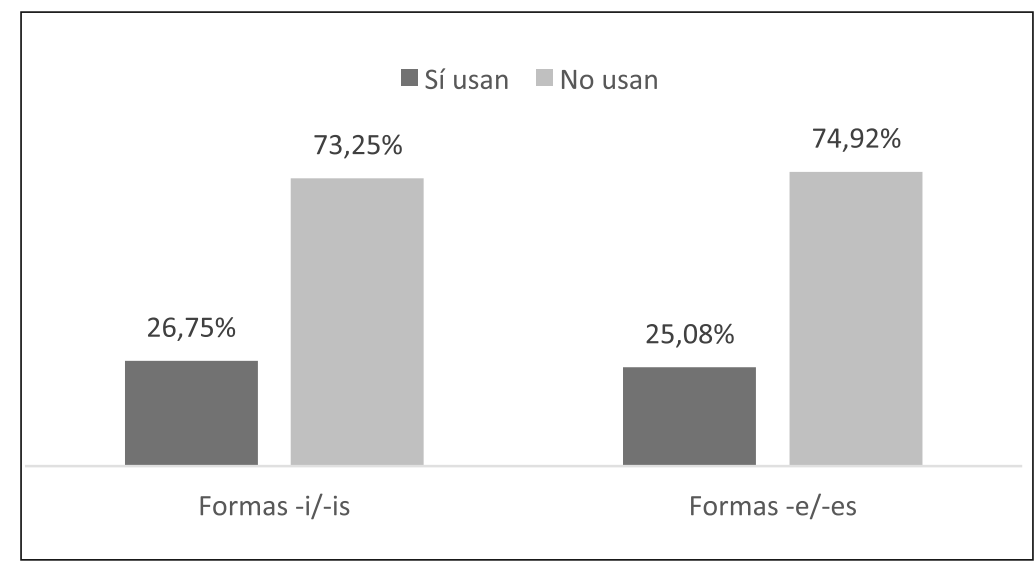

Gráfica 1. Usuarios que utilizan las terminaciones de género -i/-is y -e/-es

Con estos datos se puede confirmar que el uso de ambos tipos de terminaciones no está extendido tampoco dentro de la comunidad de habla LGTBI, pues son más los informantes que no las usan que los que sí las aplican al habla.

El uso de estas terminaciones es más prevalente entre las personas transgénero que en el resto de grupos analizados (personas transgénero y personas cisgénero). Un $46,15 \%$ de las personas transgénero afirmaron usar las terminaciones -i/-is. Estas mismas formas son usadas, en segundo lugar, por personas cisgénero (25,07\%). Es significativo que ninguna de las personas intergénero que respondieron a esta encuesta, indicó utilizarlas, pues confirman que no son utilizadas para referenciar a este grupo.

En cuanto a las terminaciones -e / -es, el 100\% de las personas intergénero que respondieron a esta encuesta afirma utilizarlas en su habla, lo que contrasta con la terminación anterior y confirma que es la flexión que este grupo prefiere para hacerse referencia. El segundo grupo en utilizar estas formas es el de las personas transgénero (61,54\%). Solo un 21,49\% de los encuestados cisgénero asegura utilizar estas desinencias. Con esta información, y como se refleja en la siguiente gráfica, parece que las terminaciones -e/-es son preferidas, frentes a las $-i /-i s$, por las personas intergénero, más susceptibles de ser referenciadas por estas: 


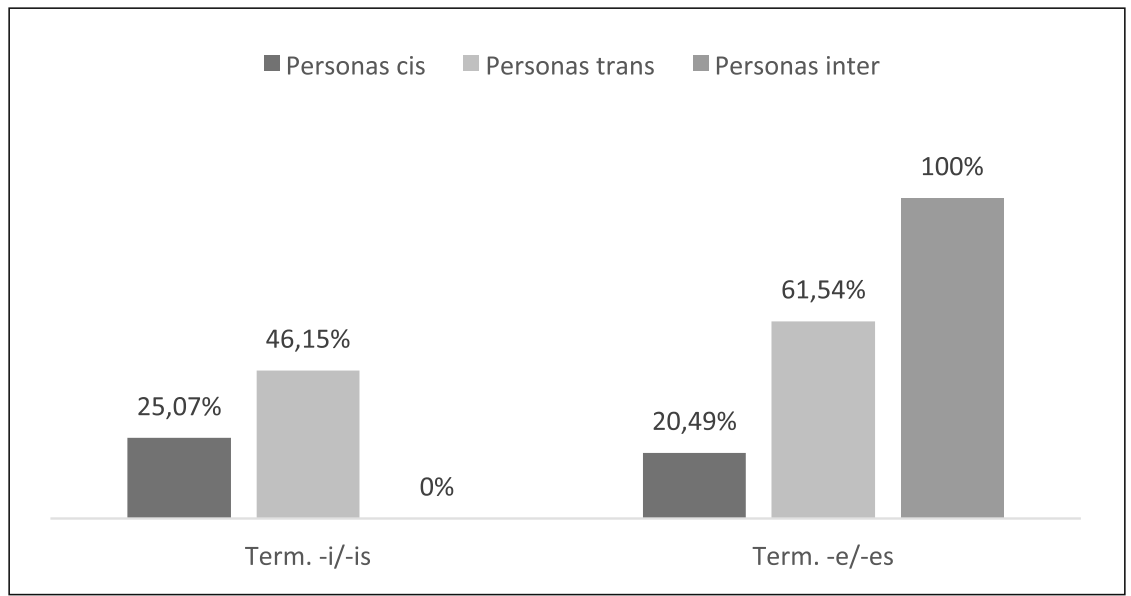

Gráfica 2. Usuarios de las nuevas terminaciones, según la correspondencia género/sexo biológico

También se ha tenido en cuenta la interpretación de los receptores de actos de habla en los que se utilizan las terminaciones objeto de estudio. Para ello se preguntó a los encuestados si interpretarían que se dirigieran a ellos aplicando estos grupos de flexiones de forma negativa, de forma positiva o como algo neutro. En la gráfica 3 tenemos datos relativos a esto, y se aprecia que el $62,96 \%$ de los informantes reciben positivamente estos actos de habla con las terminaciones en $-i$-is; lo interpreta de forma neutra un $35,80 \%$; y solo un $1,23 \%$ considera que es algo negativo. En cuanto al grupo de terminaciones -e/-es, el 50,51\% de los encuestados afirma que consideran estos enunciados como positivos, mientras que el $3,03 \%$ considera que son negativos:

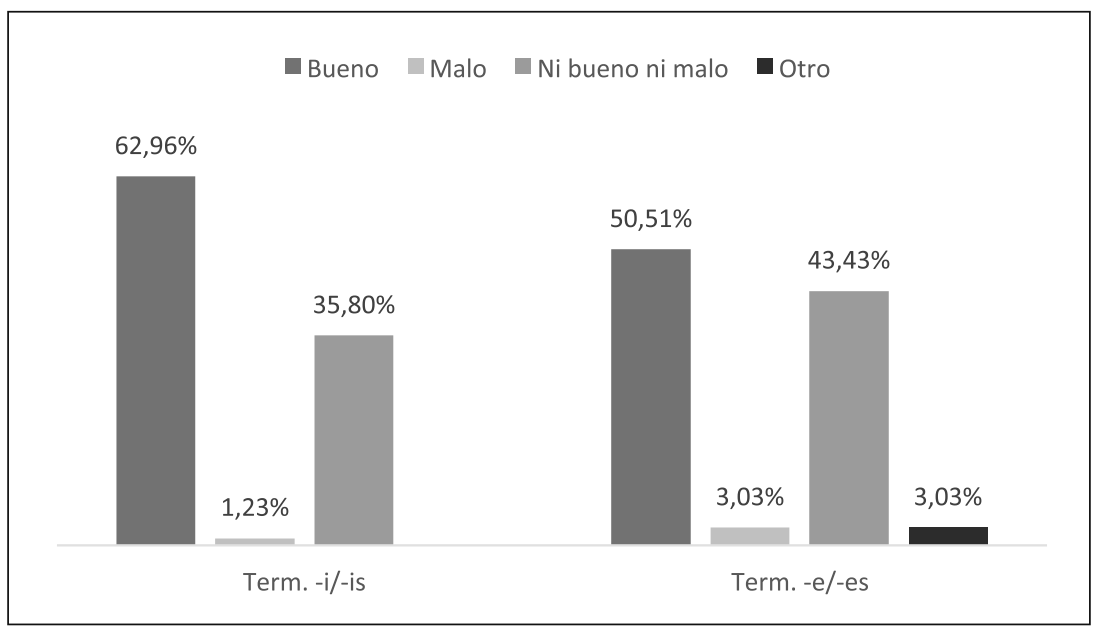

Gráfica 3. Interpretaciones de los diferentes grupos de terminaciones 
El factor edad también resulta muy significativo para este estudio, ya que se han detectado diferencias considerables en el uso de estas terminaciones atendiendo a los distintos grupos de edad de los usuarios. A menor edad, más son utilizadas estos grupos de terminaciones, siendo los usuarios entre 18 y 25 años los informantes que más las utilizan, y los mayores de 46 años, los que menos. La edad, por tanto, se muestra como una de las variables más relevantes. En la gráfica 4 se ilustra la diferencia de uso entre grupos en las diferentes flexiones de género:

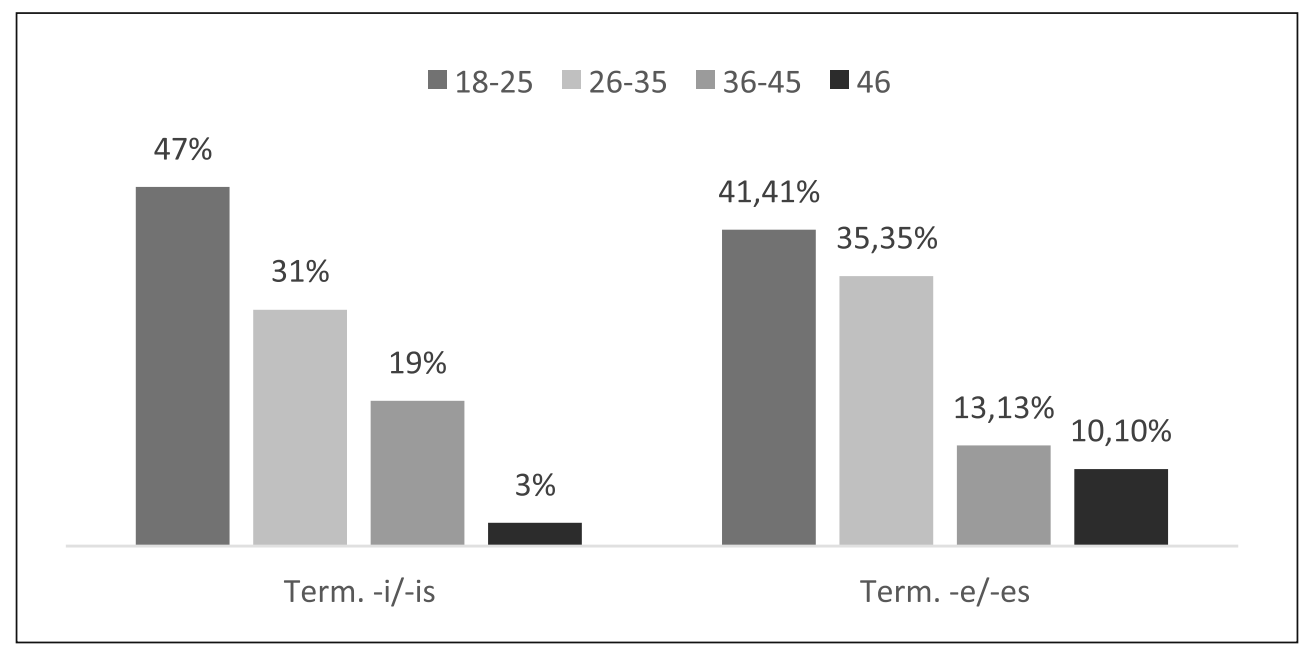

Gráfica 4. Uso de las nuevas terminaciones de género atendiendo al factor edad

Una de las preguntas de investigación que se plantean para este trabajo es quiénes son los referentes de cada grupo de terminaciones. Se han tratado, en este punto, de forma diferente ambos grupos de terminaciones, pues se parte de la premisa de que las formas $-i /$-is no se utilizan para hacer inclusión de género ni, únicamente, para hacer referencia a personas no binarias. Así pues, la pregunta planteada en la encuesta sobre quiénes son los referentes de las flexiones - $i$-is proponía varias respuestas, atendiendo a todas las identidades de género y orientaciones sexuales. La mayoría de los encuestados las usa para referirse a mujeres cis heterosexuales y hombres cis homosexuales. Después se sitúan las mujeres lesbianas, las bisexuales y mujeres transgénero, seguidas por los hombres bisexuales y las personas intersexuales. Los grupos a los que menos se hace referencia con estas terminaciones son los hombres transgénero y los hombres cisgénero heterosexuales:

Como se aprecia en la gráfica 5, la diferencia entre el grupo de usuarios más referenciados con estas terminaciones y el que menos es de apenas un punto, lo que demuestra que el objetivo de uso de esta flexión no es tanto el género como el grado de confianza, del que se hablará más adelante. 


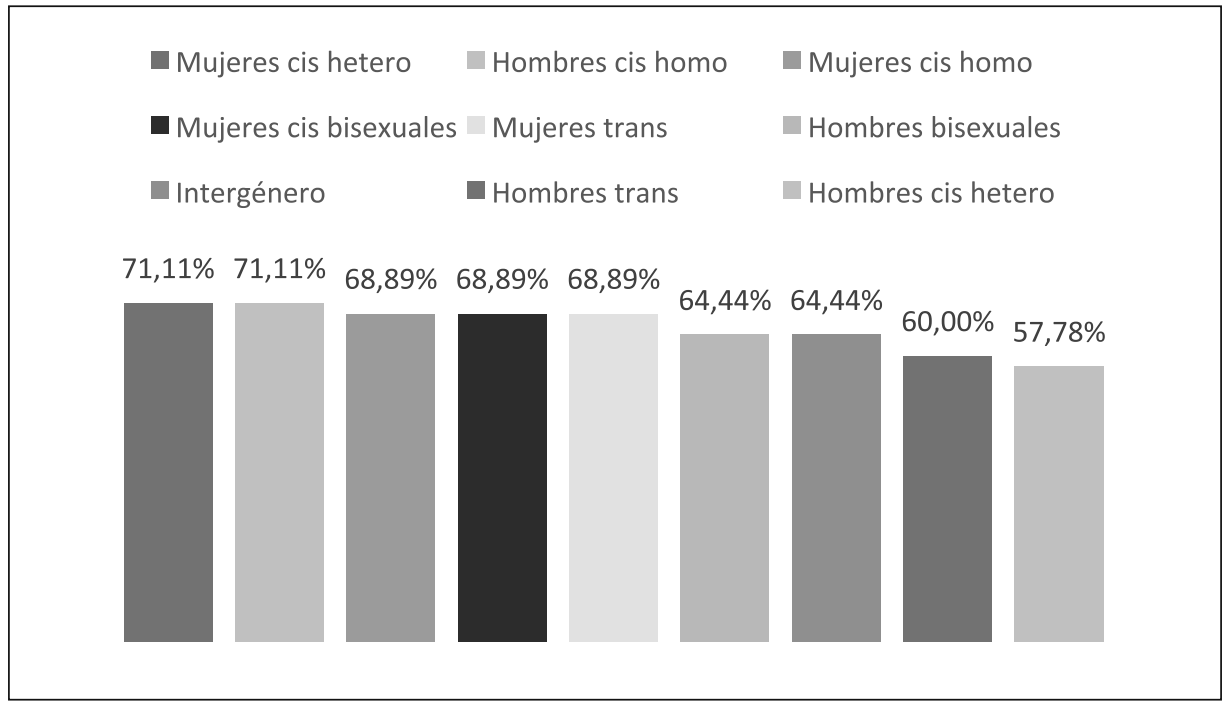

Gráfica 5. Referentes de las terminaciones $-i /-i s$

La pregunta que se planteaba sobre las terminaciones -e/-es en cuanto a los referentes es diferente, pues la duda que surge en este caso es si la intención de uso es hacer referencia a personas intergénero o bien implementar una forma de género inclusivo, como se adelantaba en el apartado 6, al ser estos los dos únicos usos que se han detectado:

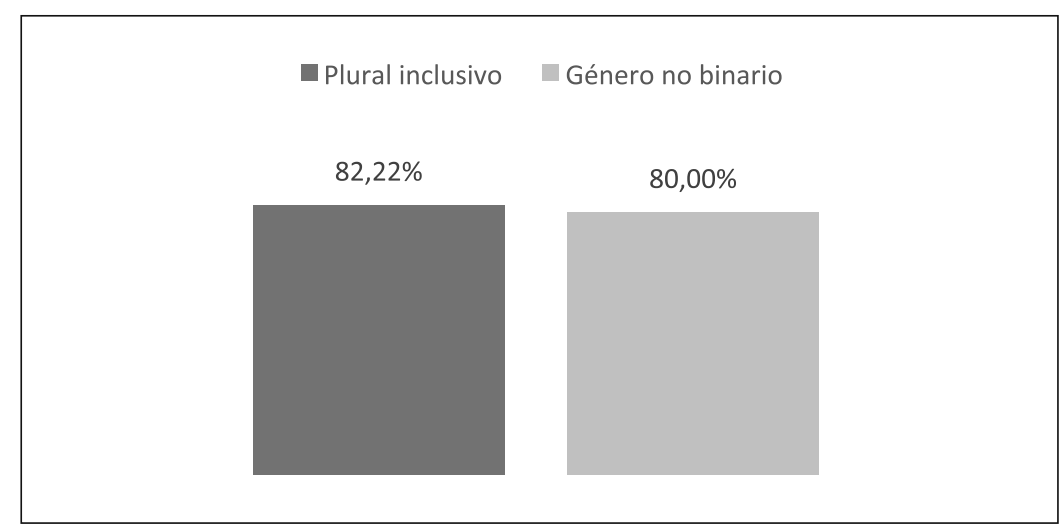

Gráfica 6. Referentes de las terminaciones -e/-es

Como se aprecia en la gráfica 6, la mayoría de encuestados utiliza estas terminaciones tanto para tratar a personas no binarias como para generar un plural inclusivo. Esta última opción es la preferida, con poco margen de ventaja.

Otra de las variables de interés en los estudios sociolingüísticos que se enmarcan dentro de la lingüística queer es la sociabilización dentro de la comunidad de habla LGTBI. Lo que 
se busca con este dato es la relevancia que tiene el contacto social con otras personas de la comunidad de habla LGTBI y la influencia que este dato tiene en el uso de estos grupos de terminaciones. Ambos son más utilizados por aquellos informantes cuyo grado de exposición a un entorno LGTBI es mayor, como queda reflejado en la gráfica 7:

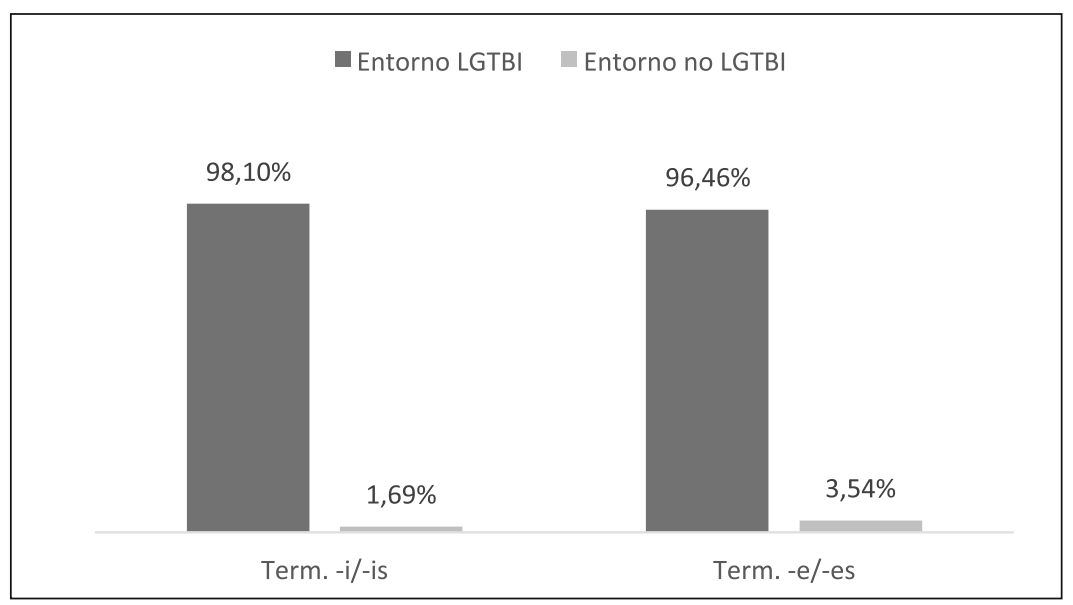

Gráfica 7. Variable de sociabilización dentro de la comunidad de habla LGTBI

Este dato nos confirma que las terminaciones -i/-is también son más habituales dentro de la comunidad de habla LGTBI y el registro coloquial de la misma, pues el porcentaje de usuarios que se integran dentro de este colectivo es muy alto.

El grado de confianza en la relación que se establece entre emisor y receptor también es significativo para utilizar las terminaciones objeto de este estudio. En la gráfica 8 se ilustra cómo, en este aspecto, las diferencias que se presentan entre ambos tipos de terminaciones son mucho más significativas que en otros puntos:

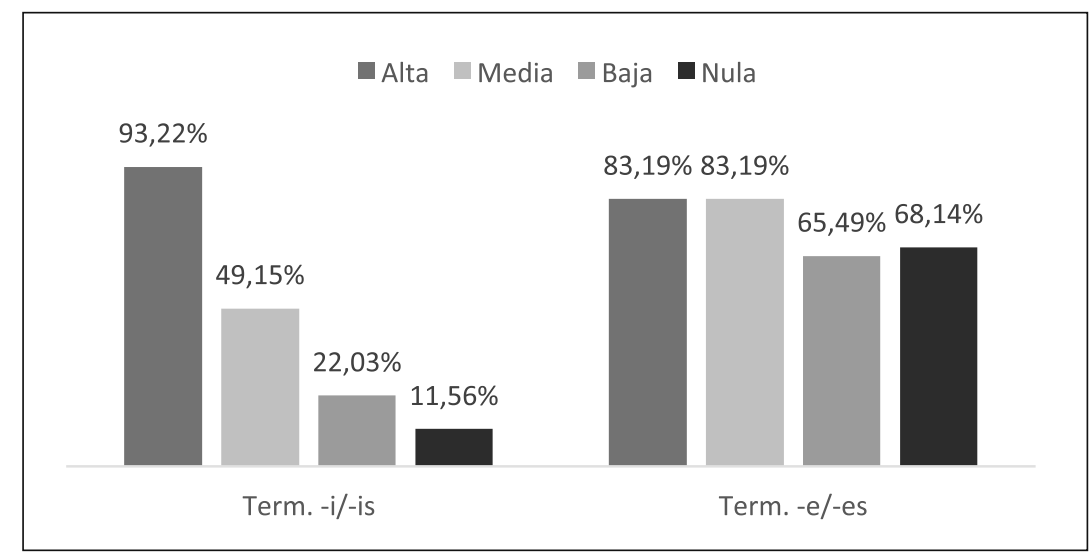

Gráfica 8. Grado de confianza entre los interlocutores 
Para que se activen las terminaciones $-i /-i s$, la confianza es un elemento de mayor relevancia. Así, el 93,22\% de los informantes la usarían con un nivel de confianza alto y, como se aprecia en la gráfica 8 , el número de hablantes que las utilizan se va reduciendo conforme se reduce este grado de confianza, hasta el punto de bajar cuarenta y tres puntos el porcentaje de usuarios que lo usarían con confianza media, y sigue descendiendo progresivamente hasta llegar a la confianza nula $(11,56 \%)$.

Con las terminaciones -e/-es se observa un comportamiento totalmente diferente en los informantes: el grado de confianza se mantiene, en todos los casos, por encima del $65 \%$. Mientras la caída es gradual en el uso de las terminaciones -i/-is, en el otro grupo de terminaciones, la confianza alta y media tiene un nivel alto de uso; y la baja y nula mantienen un nivel moderado. De esto se concluye que el grupo de terminaciones en $i$ está más asociado a entornos de confianza y, por tanto, estará presente en actos de habla afiliativos, como hemos visto en el análisis cualitativo; mientras que las terminaciones en $e$ pretenden representar algo con el lenguaje, por lo que su intención es, sobre todo, performativa.

En relación a esta última idea, los encuestados fueron preguntados por las intenciones con las que usan estas flexiones: afiliación, intensificación o atenuación ${ }^{30}$. Según los datos obtenidos para las terminaciones $-i /$ - $i s$, la intención con la que la mayoría de informantes las utiliza es la afiliación, seguida de la atenuación. Apenas son utilizadas para intensificar u ofender, como se ilustra en la gráfica 9. Las terminaciones -e/-es son usadas por la mayoría de informantes para formas actos de habla afiliativos. En menor grado, aparecen la intensificación y la atenuación. Ninguno de los informantes las utiliza con el objetivo de ofender.

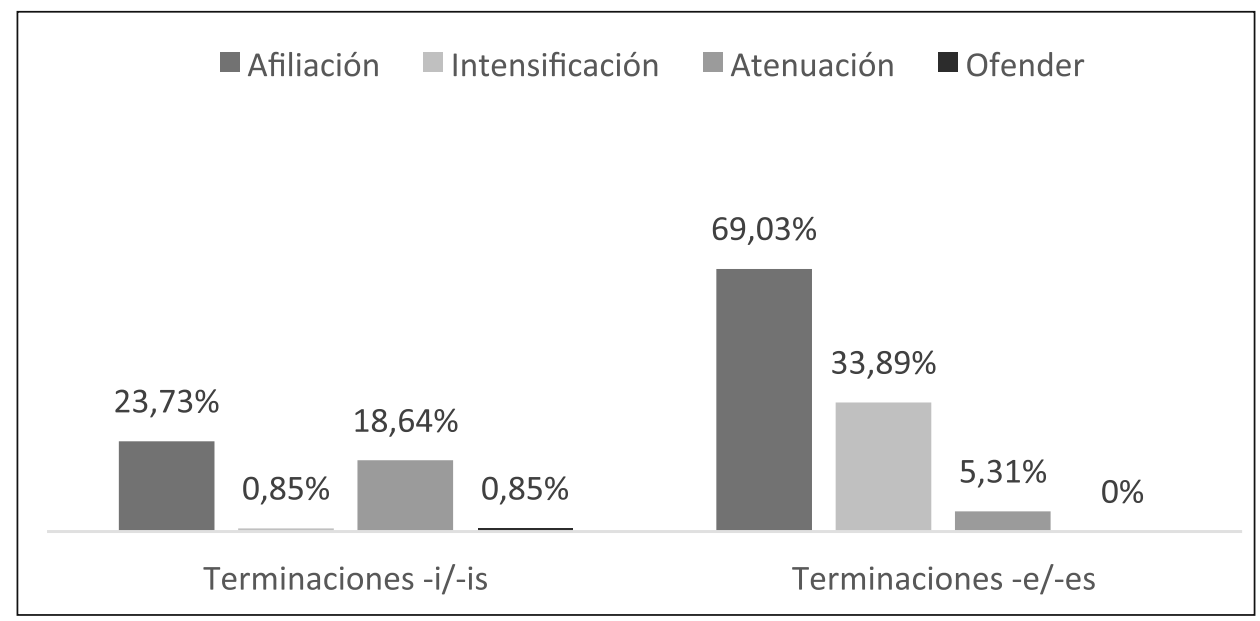

Gráfica 9. Estadística de intenciones de uso de las terminaciones

30 Las preguntas planteadas para ello en el cuestionario planteaban una definición operativa: para la afiliación se hablaba de «forma de integrarse»; para la intensificación, de «dar importancia o exagerar»; y para la atenuación, de «quitar relevancia o suavizar». 


\section{CONCLUSIONES}

Tras el doble análisis de este trabajo (cuantitativo y cualitativo) y la presentación de los resultados de los mismos, se puede concluir este texto con una enumeración de las principales conclusiones a las que se ha llegado, que servirán como conclusión del mismo:

1. Las terminaciones $-i$-is no se utilizan con la intención de hacer un género inclusivo, aunque sí que se ha detectado neutralización de genero en su uso, pues puede aplicarse tanto al femenino como al masculino, como se ha visto en los ejemplos.

2. El grupo de terminaciones -e/-es tiene un doble uso: formar un género gramatical inclusivo que lingüísticamente abarque tanto a hombre como a mujeres, eliminando así el masculino genérico; e incluir en la lengua a personas que se catalogan como no binarias y no se sienten representadas por los géneros gramaticales masculino y femenino. Ambos usos son, prácticamente, utilizados con la misma frecuencia, según la encuesta.

3. Ambos grupos de terminaciones son prototípicas de la comunidad de habla LGTBI, como indican los resultados de la encuesta. Incluimos en esta afirmación el grupo de terminaciones $-i /$ - $i s$, pues el $98,10 \%$ de los usuarios de este grupo de terminaciones pertenece al colectivo o su entorno se conforma por personas que pertenecen al mismo.

4. Aunque las terminaciones -e/-es no son muy utilizadas (solo un $25,08 \%$ de los encuestados afirmó usarlas), son los usuarios más jóvenes (entre 18 y 25 años) los que más la incluyen en sus discursos. Además, el crecimiento de uso es proporcional a la reducción de la edad de los informantes, lo que nos permite intuir que estas terminaciones serán más utilizadas con el cambio generacional.

5. Mientras que el uso del grupo de terminaciones $-i /$-is puede formar actos de habla afiliativos, entre otros (irónicos o, incluso, cómicos), y se pueden clasificar dentro de la categoría pragmática de la atenuación, las terminaciones -e/-es presentan funciones performativas, asociadas a la construcción identitaria.

\section{REFERENCIAS BIBLIOGRÁFICAS}

Albelda Marco, M. (2010). “Cómo se reconoce la atenuación? Una propuesta metodológica basada en el español peninsular hablado". En Orletti y Mariottini (eds.). (Des)cortesía en español. Espacios teóricos y metodológicos para su estudio. Roma: Università Roma Tre, pp. 41-70.

Austin, J. (1971). Cómo hacer cosas con palabras: palabras y acciones (trad. Genaro R. Carrió y Eduardo A. Rabossi). Barcelona: Paidós.

Badinter, E. (1992). XY. La identidad masculina. Madrid: Alianza.

Balza, I. (2009). "Ciudadanía y nuevas identidades de género: sobre biopolítica y teoría queer", Presente, pasado y futuro de la democracia, pp. 231-238.

Barrera Alvarado, P.A. y Ortiz Ramírez, P. A. (2007). “Tod*s, todxs, tod@s, todes y todos: el lenguaje es responsabilidad", Reflexiones marginales: http://reflexionesmarginales.com/3.0/tods-todxstods-todes-todas-y-todos-el-lenguaje-es-responsabilidad/ (09/08/2019).

Bernal, M. (2008). “¿Insultan los insultos? Descortesía auténtica vs. descortesía no auténtica en español coloquial”, Pragmatics, 18 (4), pp. 775-802.

Bonnin, J. E. (2019). “(Des)afiliación y (des)alineamiento: procedimientos interaccionales para la construcción de voz”, Pragmática sociocultural, 7 (2), pp. 231-252. 
Bravo, Diana (1999). “¿Imagen positiva vs. imagen negativa? Pragmática sociocultural y componentes del face", Oralia. Análisis del discurso oral, n. ${ }^{\circ}$ 2, pp. 155-184.

Briz Gómez, A. (1995). "La atenuación en la conversación coloquial. Una categoría pragmática". En Cortés (ed.). El español coloquial: actas del I Simposio sobre análisis del discurso oral. Almería: Universidad de Almería, Servicio de Publicaciones, pp. 103-122.

Briz Gómez, A. (1998). El español coloquial. Esbozo de pragmagramática. Barcelona: Ariel.

Briz Gómez, A. (2003). "La estrategia atenuadora en la conversación cotidiana española". En Bravo (ed.). Actas del Primer Coloquio Edice. La perspectiva no etnocentrista de la cortesía: identidad sociocultural de las comunidades hispanohablantes. Estocolmo: Universidad de Estocolmo, libro-e, pp. 17-46.

Briz Gómez, A. y Albelda Marco, M. (2010). “Aspectos pragmáticos. Cortesía y atenuantes verbales en las dos orillas a través de muestras orales". En Aleza Izquierdo, M. y Enguita Utrilla, J.M. (coords.). La lengua española en América: normas y usos actuales. València: Universitat de València, pp. 237-260.

Butler, J. (1990). "Performative acts and Gender Constitution: An Essay in Phenomenology and Feminist Theory". En Case, Sue-Ellen (ed.), Performing Feminisms: Feminist Critical Theory and Theatre. John Hopkins University Press, pp. 270-282.

Butler, J. (2002). “Acerca del término queer". En Butler, J. Cuerpos que importan. Barcelona: Paidós, pp. 313-339.

Butler, J. (2007). El género en disputa. El feminismo y la subversión de la identidad. Madrid: Espasa.

Butler, J. (2009). "Performativity, precarity and sexual politics", AIBR. Revista de Antropología Iberoamericana, vol. 4, núm. 3, pp. 321-336.

Cabral, B. E. y García, M. ${ }^{\text {a }}$ T. (2000). "Masculino/Femenino... ¿у yo? Identidad o identidades de género", AVERSO, Fascículo n¹0, Mérida.

Cano Abadía, M. (2013). "Palabras que ¿solo? hieren. Repeticiones abyectas y resignificaciones liberadoras", Thémata. Revista de Filosofia, 48, pp. 217-225.

Connell, R.W. (2003). Masculinidades. México: PUEG/UNAM.

Felipe Castelar, A. y Quintero Aguirre, F. (2012). "Performatividad y lenguaje de odio: expresiones de la homosexualidad masculina en la ciudad de Cali”, CS, Estudios sobre Latinoamérica y el Caribe con perspectiva global, 10, pp. 207-240.

Franco Martínez, A. (2019). "¿Todos/as, todxs o todes? Efectos cognitivos del uso del genérico masculino y sus formas alternativas en español”. En Sánchez Ibáñez, M., Fernández Cano, M., Pérez Bernabeus, A. y Fernández de Pablo, S. (eds.). Maricorners. Investigacioes queer en la Academia. Barcelona-Madrid: Egales, pp. 25-56.

García Meseguer, A. (1977). Lenguaje y discriminación sexual. Madrid: Cuadernos para el diálogo.

Gilmore, D. (1994). Hacerse hombre: concepciones culturales de la masculinidad. Barcelona: Paidós.

Godelier, M. (1986). La producción de grandes hombres. Poder y dominación masculina entre los baruya de Nueva Guinea. Madrid: Akal.

González Montero, S.A. (2009). "Política de la lengua. Enunciados, poder y sociedad", Desafios. Bogotá (Colombia), 20, pp. 30-80.

Gutiérrez Lozano, S. (2007). "La construcción cultural de la sexualidad masculina: un análisis discursivo". En Montesinos, R. (coord.). Perfiles de la masculinidad. Madrid: Plaza y Valdés, pp. 75-114.

Herdt, G. H. (1981). Guardians of the flutes: Idioms of masculinity. Nueva York: McGraw-Hill.

Kimmel, M. (1994). Masculinidad: El Reto Americano. México: UNAM.

Martín Zorraquino, M. y Portolés, J. (1999). "Los marcadores del discurso". En I. Bosque y V. Demonte (eds.). Nueva gramática descriptiva de la lengua española. Madrid: Espasa-Calpe, vol. 3, pp. 4051-4213. 
Mira, A. (2000). "Laws of silence: homosexual identity and visibility in contemporary Spanish culture”. En Barry J. y Morgan-Tamosunas, R. (eds.). Comtemporary Spanish cultural studies. London: Arnold publishers, pp. 241-250.

Moreno Sánchez, Á. y Pichardo Galán, J. I. (2006). "Homonormatividad y existencia sexual. Amistades peligrosas entre género y sexualidad", Revista de Antropología Iberoamericana, vol. 1, núm. 1, pp. 143-156.

Navarro-Carrascosa, C. (2019). "Resignificación y reapropiación en el español coloquial: el caso de maricón". En Cabedo Nebot, A. e Hidalgo Navarro, A. (eds.). Pragmática del español hablado. Hacia nuevos horizontes. València: Universitat de València, pp. 169-183.

Navarro-Carrascosa, C. (2020). "Caracterización del discurso de la comunidad de habla LGTBI. Una aproximación a la lingüística queer hispánica", Revista de Investigación Lingüística, 23. pp. 353-375.

Pérez Fernández-Figares, K. (2010). "Historia de la patologización y despatologización de las variantes de género". En Missé, M. y Coll-Planas, G. (eds.). El género desordenado. Barcelona-Madrid: Egalés, pp. 97-111.

Rodríguez, F. (2008). Diccionario gay-lésbico. Madrid: Gredos.

Villalba Ibáñez, C. (2018). "Atenuación: algunas claves metodológicas para su análisis”, Normas, 8, pp. 306-316.

Villalba Ibáñez, C. (2020). "Recognising Mitigation: Three Tests for its Identification", Journal of Pragmatics, 167, pp. 68-79.

Vélez-Pellegrini, L. (2008). Minorías sexuales y sociología de la diferencia. España: Montesinos.

Wójtowicz, J. (2017). Identidades subversivas: La expresión del género no binario por los hablantes de inglés de español. Cracovia: Universidad Jaguelónica de Cracovia.

Zimmermann, K. (2003). "Constitución de identidad y anticortesía verbal entre jóvenes masculinos hablantes de español”. En Bravo, D. (ed.). La perspectiva no etnocentrista de la cortesía: Identidad sociocultural de las comunidades hispanohablantes. Actas del Primer Coloquio del Programa EDICE, Stockholm, CD-ROM, pp. 47-59. 